\title{
Sexual Abstinence and Sperm Quality
}

\author{
Ahmed AlAwlaqi ${ }^{1}$, Mohamed E. Hammadeh ${ }^{1^{*}}$
}

\begin{abstract}
Background: Previous research has documented that sexual abstinence can improve sperm quality. Sexologists have reported that sperms stored in a latex condom decrease at a rate of $60 \%$ per minute.

Objective: The objective of the current review is to explore the relationship between sexual abstinence duration and other factors that affect standard and substandard semen production.

Design: A scientific review of published literature.

Main Outcome Measure: Specific focus is to discuss how sexual abstinence behaviours relate to the production, quality and efficiency of sperms and semen in relation to the different characteristics such as duration of abstinence, age, and psychological behaviours. The study will also seek to verify if there is a link between sexual abstinence and semen production or what triggers semen production in men.

Results: From the reviewed literature, data analysis on oligozoospermic samples indicated a peak motility of $30 \%$ after 1 day of abstinence. After 2 days of abstinence, the recorded average percentage of the normal sperm morphologies among the moderate and mild oligozoospermic samples ranged from $7 \%$ to $8.5 \%$. The increase of the normal sperm morphology was statistically significant $(P<0.003)$ and sperm motility $(P<0.001)$ that were in line with the average percentage production of $7.5 \%$ and $31.9 \%$, respectively. The significant sperm production was recorded between day 3 and day 8 of abstinence.

Conclusion: The data obtained supports the literature on abstinence in facilitating male infertility treatment. Thus, the data argues that so as to present the best semen samples for fertility treatment, men should collect semen sample after 3-8 days of abstinence as recommended by the World Health Organization (WHO). Patients that present normal sperms give sperm donations for cryopreservation ought to be informed not to exceed the 10-day abstinence duration as the quality of the sperms is compromised. Keywords: Sperm quality, Oligozoospermia, Sexual abstinence, Total motile sperm count, Sperm morphology
\end{abstract}

\section{Introduction}

The scientific literature estimates that male infertility accounts for $30 \%$ to $40 \%$ of infertility among couples (13). Before fertility treatments can be initiated, it remains unclear on what should be the optimal period of sexual self-restraint required to warrant maximum quality sperm is achieved. According to the World Health Organization (WHO), the abstinence time before medical examination should be between 2-7 days (4). The abstinence has been reported to help in concentrating semen, improving the percentage of the morphology of sperms, and increasing the percentage of sperm motility (5). Nonetheless, the basis of this abstinence recommendation is still debatable since it is not clear from the scientific literature. To some extent, scholars agree that no lubricants should be used as they may contain bacteria that can kill or rather destroy the produced sperms (6). The sperms should then be stored in non-spermicidal containers to increase their lifespan. For instance, sperms produced for testing should not be stored in condoms as it may affect their lifespan (7). Sperms stored in a latex condom decrease at a rate of $60 \%$ per minute. Before this masturbation, the man should have abstained from sexual activities for a period of between two and seven days (8).
Over time, it has been noted that sperms quality improves after a short period of abstinence. Much research has been done to verify and validate the above statement (9). Moreover, most medical practitioners have concurred that a limited absence from sexual activity increases the quality of semen produced by a male person (10). In as much as sperm quality is affected by periods of abstinence, several factors also need to be considered when it comes to sperm motility; lifespan and morphology (11). Sperm quality is, among others, affected by nutrition and diet of the person, lack of exercise, time of ejaculation, extended long periods of stress, drug and substance abuse, physical trauma and exposure to health hazards such as radioactivity (12). This confirms the partial role of abstinence in ensuring that the quality of sperm is adequately maintained. As a result, we could only use abstinence as a function of sperm quality while holding other factors constant (13). Despite this, medical research conducted revealed that the greatest factor affecting the sperms' quality is the level of abstinence. Most studies are interested in looking at the issues of sperm quality (14). Therefore, this means that abstinence is a weighty issue that influences the quality of sperms in both normal male individuals and men with infertility problems. 


\section{Abstinence and Ejaculate Volume}

Men without fertility problems produce lots of seminal volume with a high sperm concentration in a single ejaculation. If they have sex very frequently, they risk depleting their sperm stores. They should, therefore, give their reproductive systems enough time to replenish the ejaculated sperms (15). However, this time, should not exceed the seven days since the semen after that time is rendered useless. It is recommended that an abstinence of not more than seven days after a single ejaculation gives the body enough time to reproduce more sperms of higher quality and at the same time preventing sperm motility (16). In other words, it allows a balance of sperms within the reproduction system.

This in any way does not warrant any male to over-involve in sexual intimacy with female counterparts because he might end up depleting the quantity of sperms in his possession. Alternatively, he should concentrate on routinely flushing his system in order to maintain fresh sperms (17). After ejaculation, sperms normally need at most two days to completely refresh and recoup their numbers. According to Bedaiwy and Rizk (18), the effects of short or long abstinence periods in non-obstructive azoospermic patients usually indicate that there were low semen volume and concentration in the short abstinence period.

\section{Abstinence and $\mathrm{pH}$}

DNA normally dictate the nature of acidity or alkalinity of sperms. Because the DNA component possesses a natural acidity, the $\mathrm{pH}$ for sperms becomes automatically acidic. In instances where abstinence takes a shorter period of time, there is normally no effect it has on the overall $\mathrm{pH}$ of the semen $(19,20)$. Within the initial five days of sexual abstinence, the seminal $\mathrm{pH}$ never changes. However, with extended abstinence, the sperm $\mathrm{pH}$ consequentially changes (21). With an increasing duration of abstinence, the $\mathrm{pH}$ of the semen rose steadily due to the DNA having been damaged over time. The semen after seven days will start becoming alkaline in nature, a composition that hinders and cushions the acidic domain of the vaginal canal. It thereafter protects all the DNA inside the sperm from acidic contamination (22). This, in turn, creates an enabling environment for spermatozoa when travelling through the female reproductive tract.

\footnotetext{
Abstinence and Viscosity

Normal males are capable of producing a lot of sperms if they stay away from sex for a duration not exceeding seven days. In normal cases, men who abstain from five to a maximum of seven days produce sperms with lower viscosity. However, men with fertility issues should abstain for only forty-eight hours to ensure they produce sperms with a low viscosity which ensures that they are highly mobile $(23,24)$. Abstinence among normal men can only lower sperm viscosity if it is practised for a maximum of seven days, while in men with fertility problems it should be a maximum of two days.
}

\section{Abstinence and Sperm Concentration and Count}

Medical practitioners have researched on the morphology and motility of semen after a certain period of time and noted that it improves after a short period of abstinence. However, the situation deteriorates, and low sperm counts per millimetre are noted after a prolonged duration of sexual activity abstinence. Most men who abstain from sex for more than a day produce poor quality semen, and a few of them show normal sperm count with no improvement at all (25).

This after a massive research has been proved wrong and no medical study has come out to support that statement over the years. However, most people have strongly held out that abstinence improves sperm quality and sperm count at large (26). Most medical researchers have encouraged to engage frequently in sexual activities, if at all, they want to improve their sperm count quality as well as seminal motility and shape during ejaculation. The time period between two ejaculations determines the quality and rather the number of spermatozoa produced per ejaculation $(27,28)$.

In many cases, couples who want to conceive are advised not to waste any chance. They should have a sexual activity as this increases their chance of conceiving and having a baby. Men are also advised to carry out sexual activity during mornings as that is when their sperm count is high $(29,30)$. According to researchers, the sperm count in men is generally more during the mornings. Quite notably, this is also the period that the urge to have sex in men is generally considered high.

\section{Abstinence and Sperm Viability}

According to Elzanaty's study, there is a correlation between poorer results and longer periods of abstinenceone previous study established abstinence for longer than 10 days prior to IUI resulted in a $3 \%$ success rate of getting pregnant. This means that even though abstinence increases the sperm quality, exaggerated abstinence could lead to lower sperm qualities infertile men (26). When sperms stay in the epididymis for more than seven days, say ten days, they become exposed to environmental agents such as heat eventually rendering them useless (32). On exposure to these environmental agents for a period of about 10 days, the semen starts becoming stale and is no longer fertile meaning that its quality has been lowered (33). As demonstrated above, abstinence has no consequence for the case of normal couples. Men experiencing limited sperm counts should not in any way abstain for more than two days before the intercourse (33). Couples intending to have a child are required to practice sexual intimacy continuously in order to increase their chances of conceiving (34).

\section{Abstinence and Sperm Motility}

Despite normal recommendations of giving sperm specimens for further study after 2 to 7 days of abstinence (30), while Mitchell et al argues that abstaining for 1 day will result in the best quality semen. The number of motile 
sperms produced by oligospermia male increases within 48 hours of abstinence. Since they have an infertility issue they need to ejaculate more often to increase the quality of sperm, they produce per single ejaculation (36). Analysis done by various researchers has shown that mobility of sperm count is reduced after an average of a day's abstinence if men had low sperm counts (37-39).

According to the study of Freund (40), infrequent or rather irregular ejaculation that comes as a result of abstinence can sometimes interfere with both the immobile and normal sperms. This has adverse consequences especially with reference to conception. As a result, some studies have proposed that fertile men should ejaculate at least three times a week to ensure a proper amount of motile and normal sperm (41). A study conducted by Gerris (42) to investigate the effect that men's short-lived duration of abstinence has on DNA damage, motility, and sperm morphology found out that one-day abstinence has no substantial variation in the entire mobile sperm count (TMSC) for two periods (between 18-30 hours and 3-5 days of abstinence).

\section{Abstinence and Sperm Morphology}

Prolonged stay without sex makes a normal man to produce a higher volume of sperms in a single discharge of sperms (39). However, in this case, the concentration of sperms is much lower, and their morphology assessment is very low compared to sperms produced within a shorter period of abstinence (43). Therefore, medical experts recommend that if sperm quality improvement is needed, then a man should abstain for a very short period of time lasting not more than a day. There have been misconceptions that if a man abstains from sex for a longer period of time, he improves the shape and his sperms' ability to swim (44).

According to Jungwirth et al (45), different parameters of the semen have a strong relationship with the duration of abstinence, more so in regard to subnormal semen. There is a degradation in the quality of semen after two days of abstinence among males with infertility factors (45). Continued regular ejaculation leads to the production of semen that has not completely matured up, and this may lead to ejaculation of semen that is not fertile (46). When one ejaculates each single day, semen morphology deteriorates together with its motility (47).

\footnotetext{
Abstinence and Sperm DNA Integrity

Normally, it is advisable that men with sperm counts that are low to practice sexual abstinence to help them improve on their sperm count. New research, however, shows that excessive abstinence may cause tremendous damage to the sperm DNA of the sperm that is produced (48). Sperm will last for two weeks before it breaks down and get reabsorbed into the body. Occasional ejaculation helps in maintaining the safety of the sperm's DNA since longer storage of semen exposes it to the risk of destruction (49). Most often, it has been noted that the high-quality semen is usually produced by people who have frequent sex
}

number of times. The semen they produce contains undestroyed DNA and is very fertile (50). Most men who regularly have sex are likely to impregnate ladies who are in their ovulation period since their sperms are not stale and are more mobile (51). A couple of research findings have examined the existing relationship between the absence of ejaculation and DNA packaging. According to Allahbadia and Merchant (52), there is no relationship that exists between frequent ejaculation and DNA condensation. In their findings (53), Jensen et al stated that the complex of DNA-protein remains unaffected by up to 12 hours or 7-day abstinence.

\section{Abstinence and Sperm Membrane Integrity}

Quality sperms should have a thin membrane that allows for easy release of acrosome in the uterus. The integrity of the sperm membrane can be increased with a certain period of abstinence depending on the fertility levels of men. Excessive abstinence longer than the recommended interferes with the integrity of the membrane $(54,55)$. In normal men, for instance, the sperm membrane hardens after seven days of abstinence rendering the sperms produced uselessly. Normal men should not abstain for more than seven days if they want a thin and integral sperm membrane. For men with fertility problems, abstinence for more than 48 hours makes the sperm membrane harder.

\section{Abstinence and Acrosome Integrity}

Based on the study of Khera and Lipshultz (56), undertook a retrospective research to assess the relationship that exists between duration and acrosome index taken in sexual abstinence in the analysed semen specimen of normozoospermic and oligozoospermic individuals against teratozoospermia. The acrosome index indicated a significant reduction $(P<0.001)$ was documented between normozoospermic samples $(\mathrm{n}=1264)$ on a 5 -day abstinence among the highest value of $10.2 \pm 3.6 \%$ on day 2 and 8.5 $\pm 4.0 \%$, while on the other hand, the highest value that was recorded from the oligozoospermic samples $(n=536)$ was $8.7 \pm 3.5 \%$ after day 1 of abstinence. Moreover, the sperm count reduced to $6.8 \pm 3.7 \%(P<0.004)$ after 5 days of abstaining. From this result, it is clear that after a short sexual abstinence, maximum acrosome index is likely to be received.

\section{Association Between Sperm Quality, Testosterone Hormone and Abstinence}

Some research has shown that men in marriage have lower testosterone as compared to bachelor's (57). Comparing single and married men, the former has higher levels of testosterone than later counterparts; and those who reported being in happy and conflict-free marriages possess reduced male hormone levels in relation to their counterparts in rocky unions (58). Higher testosterone levels exist among childless fathers compared to the married men who have children (59). Medical experts and researchers have found out that since men with infertility problems produce less sperm per ejaculation, they need to ejaculate 
more to match the ejaculation of a normal healthy person (60). In this case, they are able to empty their epididymis since they ejaculate more. This gives a chance for their testosterones to produce a new batch of healthier sperms which are fertile and mobile enough.

\section{Abstinence and Fertility Potential}

Studies show that men who frequently ejaculate have increased the quality of their semen and also their chance of producing fertile sperms (61). According to the study of Lishko and Kirichok (62), normally there is a correlation between poorer results and the longer abstinence periods. This means that even though abstinence increases the sperm quality, exaggerated abstinence could lead to lower sperm qualities infertile men (63). However, normal men experience high the sperm count and are able to produce quite a large quantity of sperms per single ejaculation (64). Fertile men are therefore recommended to take an abstinence period of not more than seven days. After 7 days, their sperms start becoming stale and useless for fertility purposes (65).

The number of motile sperms produced by oligospermia male persons increases within 48 hours of abstinence. Since they have an infertility issue, they need to ejaculate more often to increase the quality of sperm they produce per a single ejaculation. The time taken by two different individuals to produce a new batch of quality sperms differs (66). This is due to the fact that a fertile man and infertile man take different time for their tester ones to produce semen. In fact, the quantities of sperm produced per ejaculation by a fertile and an infertile man differ by a great margin (67).

\section{Material and Methods}

The current study review was in 10 retrospective studies carried out between 2010 and 2014. The patients assessed were all undergoing infertility tests. These samples had been evaluated for regular medical checkups intending to undertake intrauterine insemination (IUI). In line with WHO criteria, oligozoospermic specimens included all those concentrations of sperms lower than $20 \times 106$ per $\mathrm{mL}$. In addition, samples with lower than $0.2 \times 106$ per $\mathrm{mL}$ to $0.4 \times 106$ per $\mathrm{mL}$ were recorded as severe oligozoospermic. In contrast, samples with a sperm count of between 4 $\times 106$ per $\mathrm{mL}$ and $10 \times 106$ per $\mathrm{mL}$ were recorded as moderate oligozoospermia. Mild oligozoospermia included cases with a sperm count of 10-19 $\times 106$ per mL. Normal samples had more than $20 \times 106 \mathrm{~mL}$ of sperm count.

The mean level of ejaculate sperm volume among the samples, sperm concentration, and motile sperm was evaluated in line with the WHO. Also, morphology and normal sperm percentage were determined for severe cases of oligozoospermia. In every ejaculate, the full sperm count was analysed by multiplying the volume and concentration of semen across the samples. In addition, sperm motility and density was performed by multiplying percentage sperm mobility and total sperm count. In each group, and depending on the period of abstinence, the samples were categorised into various groups; between 0-1 days, 2-8 days, and 9-14 days. All the samples grouped into 9-14 days were mainly few and as a result was combined into two groups: 9-11 and 12-14 days.

\section{Results and Discussion}

The results showed that the impact of sexual abstinence on sperm mobility, total sperm count, and concentration, apart from morphology, among all the 3 groups with oligozoospermia was similar. As such, to increase statistical power, the 3 oligozoospermic groups were examined by combining them except for their sperm morphology. First, the mean semen volume in every ejaculate in normal samples and oligozoospermic samples was observed to gradually increase as individuals abstained. Specifically, there was a significant increase $(P \leq 0.001)$ in the average semen volume between $2.1 \pm 1.2 \mathrm{~mL}$ between day 0 and day 1 , and also $3.7 \pm 2.1 \mathrm{~mL}$ on 9-14 days of abstaining. Notably, the maximum observed volume of sperm concentration was noted on day 8 and day 11 among oligozoospermic samples. However, the peak volume of normal samples was recorded on day 10 through day 14 . However, the subsequent sperm increase after 4-day abstinence was not significant for the oligozoospermic samples. Even so, the statistical significance of normal samples was observed on day 5 through to day 8 of abstinence to reach a statistical significance of $P \leq 0.001$.

The concentration of sperms after day 1 of abstinence ranged from 0.3 to $19 \times 10^{6} \mathrm{~mL}$. After day 1 , there was a peak sperm concentration upon abstaining with a sperm concentration of $7.8 \pm 5.1 \times 10^{6} \mathrm{~mL}$. The value represents a nonsignificant and mild reduction in the succeeding days after sustenance. Irrespective of the significant reduction of sperm concentration on day 5 , there was an insignificant mean reduction in the concentration of the sperms in the subsequent days. Similarly, the normal samples also showed insignificant $(P>0.032)$ decline in the mean concentration of sperm between 1-2 days of abstinence. The decline was then marked with a significant $(P<0.001)$ increase in average sperm concentration on day 3 and continued to day 6 to reach $60.2-74.3 \pm 21.5 \times 10^{6} \mathrm{~mL}$. Although the peak concentration continued to day 8 , there was no statistical significance between the concentration in day 6 through day 8 .

Among the oligozoospermic samples, the total sperm count also increased on day 2 and day 3 of abstinence mainly because if the high levels of semen volume. The increase in sperm count was statistically significant in days 3 and 4 . Nonetheless, the peak volume declined after 5-day abstinence as a result of reduced concentration of sperms. Even if the peak sperm count that was documented after day 7 of abstinence, the increased sperm count between days 6 and 7 was not statistically significant. In the normal samples, there was insignificant sperm count on day 1 of abstinence, while an increase in significance was noted by day 7 . Sexual abstinence from day 3 to day 6 presented a mean sperm count that was statistically significant $(P<0.001)$. However, there was no statistical signifi- 
cant observed with the additional total mean sperm count from day 11 through day 14 of sexual abstinence.

Another interesting observation was made with the peak mean percentage while assessing sperm motility after day 1 of sexual abstinence. The motility was $30.1 \% \pm$ $19 \%$. After day 1 , there was a gradual and significant mortality $(P<0.001)$ through day 5 of abstinence compared to day 1 at $33.1 \% \pm 21.2 \%$ through day 7 . After day 8 , the sperm motility appeared to be stagnant and then declined abruptly to reach $26 \% \pm 15.6 \%$ on $11-14$ days of abstinence. In contrast, the normal sample's mean percentage was $42.5 \% \pm 21.3 \%$ after day 1 abstinence. The high-level mortality was reached on day 6 . A decrease in mortality was recorded between day 8 and 10 of abstinence, with an additional significant drop in mortality $(P<0.002)$ recorded on day 11 through day 14 , to reach mortality values of $32.1 \% \pm 19.8 \%$. Thus the maximum mean motility among normal samples is observed in day 10 of abstinence before declining at 11-14 days of abstaining.

The study findings elaborate that among oligozoospermic samples, the reduction in their mean percentage in sperm morphology and motility are inversely correlated with the duration of abstinence (68). Abstinence that lasts a day is linked to improved sperm quality. Analysis of normal samples indicates an increase in sperm quality from day 3 to day 7 in terms of percentage motility, while the improved morphology is attained on day 10. Notably, the percentage of effective fertilisation is positively associated with successful oocyte fertilisation. The current findings are in line with recent reports (69-71) that have documented the importance of abstinence in improving total sperm morphology, sperm count, and motility among male patients that present with low sperm count (72). As such, pooling the sequential ejaculates is highly recommended in efforts to improve infertility problems in men and improving fertilisation success (73).

Storey et al (72) have reported that a decline in semen volume once the samples have been collected after different abstinence periods of 3-8 days is positively related to improved sperm quality. In agreement with the findings, Suarez and Sukprasert et al $(73,74)$ have also reported that the mean semen volume is related to increased sperm morphology and motility as the rate of abstinence increases from day 3 to day $8(75,76)$. However, after day 8 the level of motility and percentage morphology reduces meaning there is no benefit in semen volume that can be obtained beyond day 9 of abstinence among oligozoospermia patients (77). In addition, based on the current review observations, it can be argued that the different semen parameters are largely correlated with the duration of abstinence, and mainly among males with low sperm counts $(78,79)$. After just 7 days of abstinence, sperm from oligozoospermia samples or male patients initiates a process of quality decline $(79,80)$. As such, the data is in line with the WHO guidelines that sexual abstinence should be observed within 2-7 days in efforts to treat infertility problems (80).

\section{Conclusion}

In conclusion, the study findings report that patients with male infertility that intend to undergo fertility and fertilisation exercises should collect semen between day 2 and day 7 of abstinence so as to get the highest chance of sperm quality. The total mobile sperm count can increase when there is prolonged sexual abstinence, but abstain beyond day 7 should be discouraged in efforts to reduce the decline of sperm quality associated with a prolonged abstinence duration. In contrast, persons with normal sperm count or donors should do so on day 6 and 10 of abstinence. Nevertheless, abstaining for more than 10 days has to be discouraged because past this period the sperm quality in terms of motility and morphology is undermined. The findings further present the strongest evidence in support of abstinence. On the contrary, however, sexual abstinence can deter conception in the case of couples who are on medication pertaining to fertility complications. In the review current findings, it can be concluded that men who frequently have sex regularly produce the best fertile semen containing undestroyed DNA. This regular sexual culture avails higher chances of these men to fertilise during ovulation period since their sperms are highly mobile and morphologically intact. In addition, their sperms possess a higher likelihood of surviving more because they have matured enough, able to swim comfortably up the vagina and are able to fuse with the ovum easily hence causing pregnancy. However, it is advisable that men experiencing infertility conditions should practice shorter abstinence periods so as to improve the quality and efficiency of their semen.

\section{Ethical Issues}

Not applicable.

\section{Conflict of Interests}

None.

\section{Financial Support}

None.

\section{References}

1. Hu JCY, Seo, B. K., Neri QV, Rozenwaks Z, Palermo G. D. The role of HA selection on spermatozoon competence. Human Reprod. 2012;27(2):27-73. doi: 10.1093/humrep/27. s2.73

2. Wyns C. Fertility preservation: current prospects and future challenges. Gynecol Endocrinol. 2013;29(5):403-7. doi: 10.3109/09513590.2012.754872.

3. Ellekilde BJP. Semen analysis from an epidemiologic perspective. Asian Journal of Health. 2013;12(1):91-104.

4. Basu SC. Male reproductive dysfunction. New Delhi: Jaypee Brothers; 2012.

5. Weschler T. Taking Charge of Your Fertility. New York: Harper Collins; 2012.

6. Hammoud AO, Gibson M, Peterson CM, Meikle AW, Carrell DT. The impact of male obesity on infertility: a critical review of the current literature. Fertil Steril. 2008;90(4):897904. doi: 10.1016/j.fertnstert.2008.08.026.

7. Jain T, Gupta RS. Trends in the use of intracytoplasmic sperm injection in the United States. N Engl J Med. 2007;357(3):251-7. 
8. Showell MG, Brown J, Yazdani A, Stankiewicz MT, Hart RJ. Antioxidants for male subfertility. Cochrane Database Syst Rev. 2011;(1):CD007411. doi: 10.1002/14651858. CD007411.pub2.

9. Soliman A, Yassin M, De Sanctis V. Intravenous iron replacement therapy in eugonadal males with irondeficiency anaemia: Effects on pituitary-gonadal axis and sperm parameters: a pilot study. Indian J Endocrinol Metab. 2014;18(3):310-6. doi: 10.4103/2230-8210.131158.

10. Esteves SC, Miyaoka R, Agarwal A. An update on the clinical assessment of the infertile male. San Paulo Clinic. 2011;66(4):691-700.

11. Henkel R, Hajimohammad $M$, Stalf $T$. Influence of deoxyribonucleic acid damage on fertilisation and pregnancy. Fertil Steril. 2004;81(4):965-72.

12. van Anders SM, Tolman RM, Volling BL. Baby cries and nurturance affect testosterone in men. Horm Behav. 2012;61(1):31-6. doi: 10.1016/j.yhbeh.2011.09.012.

13. Pellestor F, Girardet A, Andreo B. Effect of long abstinence period on human sperm Quality. Int J Fertil Menopausal Stud. 1994;39(5):278-82.

14. Agarwal A, Aitken RJ, Alvarez JG. Studies on Men's Health and Fertility. New York: Humana Press; 2012.

15. Avendaño C, Franchi A, Taylor S, Morshedi M, Bocca S, Oehninger S. Fragmentation of DNA in morphologically normal human spermatozoa. Fertil Steril. 2009;91(4):107784. doi: 10.1016/j.fertnstert.2008.01.015.

16. Baker HW, Burger HG, de Kretr DM, et al. Factors affecting the variability of semen analysis results in infertile men. Int J Androl. 1991;4:609-622.

17. Balasch J, Gratacos E. Delayed Childbearing: Effects on fertility and the outcome of pregnancy. Curr Opin Obstet Gynecol. 2012;24(3):187-93.

18. Bedaiwy MA, Rizk B. Fertility Preservation: Advances and Controversies. Jp Medical Ltd; 2014.

19. Bechtel S, Stains L. Men's Health Books -- Sex: A Man's Guide. Emmaus, Pa: Rodale Press; 2011.

20. Bentley GR. Infertility in the Modern World: Present and Future Prospects. Cambridge: Cambridge University Press; 2012.

21. Carlson AE, Camino D, Quill TA. Pharmacological targeting of native CatSper channels reveals a required role in the maintenance of sperm hyperactivation. London: Routledge; 2013.

22. Carlsen E, Petersen JH, Andersson AM, Skakkebaek NE. Effect of ejaculatory frequency and season on variation in semen quality. Fertil Steril. 2004;82(2):358-66.

23. Carlsen E, Andersson AM, Petersen JH, Shakkebaek NE. History of febrile illness and variation in semen quality. Hum Reprod. 2003;18:2089-2092.

24. Carrell DT. Paternal Influences on Human Reproductive Success. Cambridge: Cambridge University Press; 2013.

25. Chandra A, Mosher WD, Copen C; Division of Social Statistics, National Centre for Health Statistics. Sexual Behaviour, sexual attraction, and sexual identity in the United States: Data from the 2006-2008 national survey of family growth. National Health Statistics Reports; 2011. https://www.cdc.gov/nchs/data/nhsr/nhsr036.pdf.

26. Yeung C. Sperm quality and function tests. In: Nieschlag E, Behre HM, Nieschlag S, eds. Andrology, Male Reproductive Health and Dysfunction. Berlin: Springer-Verlag; 2011.

27. Boylan M. Medical Ethics. London: Routledge; 2014.

28. Correa-Pérez JR. Intrasubject abstinence and quality of sperm. Fertile Steril. 2005;83:1588-9.
29. Cooper TG, Noonan E, von Eckardstein S, et al. World Health Organization reference values for human semen characteristics. Hum Reprod Update. 2010 ;16(3):231-45. doi: 10.1093/humupd/dmp048.

30. De Jonge C, LaFromboise M, Bosmans E, Ombelet W, Cox A, Nijs M. Influence of the abstinence period on human sperm quality. Fertil Steril. 2004;82(1):57-65.

31. Elzanaty S. Time-to-ejaculation and the quality of semen produced by masturbation at a clinic. Urology. 2008;71(5):883-8.

32. Sigman M, Lipshultz L, Howard S. Office evaluation of the subfertile male. In: Lipshultz L, Howards S, eds. Infertility in the Male. Cambridge: Cambridge University Press; 2011.

33. Esteves SC, Zini A, Aziz N, Alvarez JG, Sabanegh ES Jr, Agarwal A. Critical appraisal of World Health Organization's new reference values for human semen characteristics and effect on diagnosis and treatment of subfertile men. Urology. 2012;79(1):16-22. doi: 10.1016/j.urology.2011.08.003.

34. Evans C. Forty beads: The Simple, Sexy Secret for Transforming Your Marriage. Philadelphia: Running Press; 2011.

35. Mitchell JH, Cawood E, Kinniburgh D, Provan A, Collins AR, Irvine DS. Effect of a phytoestrogen food supplement on reproductive health in normal males. Clin Sci (Lond). 2001;100(6):613-618

36. Evers JL, Collins JA, Vandekerckhove P. Surgery or embolisation for varicocele in subfertile men. Cochrane Database Syst Rev. 2001(1):CD000479. doi:10.1002/14651858.cd000479

37. Elzanaty S, Malm J, Giwercman A. Duration of sexual abstinence: epididymal and accessory sex gland secretions and their relationship to sperm motility. London: Routledge; 2012.

38. Gurevich R. Sperm count testing and semen analysis. http:// pregnancylane.com/male-fertility-check-up-singapore/

39. Falcone T, Hurd WW. Clinical reproductive medicine and surgery. 2nd ed. Philadelphia: Mosby; 2013.

40. Freund M. Effect of frequency of emission on semen output and an estimate of daily sperm production in men. J Reprod Fertil. 1963;6:269-85.

41. Garnick M. Does frequent ejaculation help ward off prostate cancer? Harvard Medical School Prostate Knowledge. Harvard University. http://www.harvardprostateknowledge. org/does-frequent-ejaculation-help-ward-off-prostatecancer. Accessed 9 February 2013.

42. Gerris J. Methods of semen collection not based on masturbation or surgical sperm retrieval. Hum Reprod Update. 2011;5(3):211-5.

43. Goldstein M, Schlegel PN. Surgical and medical management of male infertility. Cambridge: Cambridge University Press; 2013.

44. Levitas E, Lunenfeld E, Weiss N, et al. The relationship between duration of sexual abstinence and semen quality: analysis of 9,489 semen samples. Fertil Steril. 2014;83;16801696.

45. Jungwirth A, Diemer T, Dohle GR, et al. Guidelines on Male Infertility. European Association of Urologists; Mar 2013.

46. Gosalvez J, Gonzalez-Martinez M, Lopez-Fernandez C, Fernandez JL, Sanchez-Martin P. Shorter abstinence decreases sperm deoxyribonucleic acid fragmentation in the ejaculate. Fertil Steril 2011;5:1083-1086.

47. Jensen TK, Swan SH, Skakkebaek NE, Rasmussen S, Jørgensen N. Caffeine intake and semen quality in a population of 2,554 young Danish men. Am J Epidemiol. 
2011;171(8);883-891.

48. Hamada U, Agarwal A. Unexplained male infertility potential causes and management. Hum Androl. 2011;1(1):2-16.

49. Hahn K. Fertility facts: Hundreds of tips for getting pregnant. San Francisco: Chronicle Books; 2012.

50. Hinz S, Rais-Bahrami S, Kempkensteffen C, Weiske WH, Miller K, Magheli A. Effect of obesity on sex hormone levels, antisperm antibodies, and fertility after vasectomy reversal. Urology. 2010;76(4):851-856. doi:10.1016/j. urology.2010.01.055.

51. Hutchins AI. The Infertility Handbook: The complete Resource for Couples Longing to Have a Baby. Wollombi: Exile Pub; 2011.

52. Allahbadia G. Intrauterine InseminationRotunda Medical Mumbai, India: Technologies (P) Ltd; 1998.

53. JJensen JR, Morbeck DE, Coddington CC, III. Fertility Preservation. Mayo Clin Proc. 86(1):45-49. doi:10.4065/ mcp.2010.0564.

54. Kaplan K. Sperm made from stem cells could aid men with fertility problems. Los Angeles Times. 2011. http://articles. latimes.com/2011/aug/05/news/la-heb-sperm-made-fromstem-cells-20110805.

55. Kruger TF, Menkveld R, Stander FS, et al. Sperm morphologic features as a prognostic factor in vitro fertilisation. Fertil Steril 1986;46:1118-1123.

56. Khera \& Lipshultz, L. I. (2014). Evolving approach to Men's fertility.UrolClin North America, 35(2), 183-199.

57. Lenzi A, Lombardo F, Salacone P, Gandini L, Jannini EA. Stress, sexual dysfunctions, and male infertility. J Endocrinol Invest. 2003;26(3 Suppl):72-76.

58. Levine BA, Grifo JA. Intrauterine insemination and male subfertility. Urol Clin North Am. 2008;35(2):271-276, ix. doi:10.1016/j.ucl.2008.01.002.

59. Le Lannou D, Colleu D, Boujard D, Le Couteux A, Lescoat D, Segalen J. Effect of duration of abstinence on maturity of human spermatozoa nucleus. Arch Androl. 1986;17(1):3538.

60. Levitas E, Lunenfeld E, Weiss N, et al. Relationship between the duration of sexual abstinence and semen quality: analysis of 9,489 semen samples. Fertil Steril. 2005;83(6):1680-1686. doi:10.1016/j.fertnstert.2004.12.045.

61. Levitas E, Lunenfeld E, Weisz N, Friger M, Har-Vardi I, Potashnik G. Relationship between sexual abstinence duration and the acrosome index in teratozoospermia semen: analysis of 1800 semen samples. Andrologia. 2006;38(3):110-2.

62. Lishko PV, Kirichok Y. The role of Hv1 and CatSper channels in sperm activation. J Physiol. 2010;588(Pt 23):4667-4672. doi:10.1113/jphysiol.2010.194142

63. London Fertility Centre. Semen analysis and semen freezing. http://www.spirehealthcare.com/london-fertility-centre/ our-treatments-and-facilities/a-z-of-fertility-treatments/ semen-analysis-and-semen-freezing/. Accessed July 1, 2014.

64. Levitas E, Lunenfeld E, Weiss N, et al. Relationship between the duration of sexual abstinence and semen quality: analysis of 9,489 semen samples. Fertil Steril. 2005;83(6):1680-1686. doi:10.1016/j.fertnstert.2004.12.045

65. Oldereid NB, Gordeladze JO, Kirkhus B, Purvis K. Human sperm characteristic during frequent ejaculation. J Reprod Fertil. 1984;71:135-40.

66. Maggi M, Buvat J, Corona G, Guay A, Torres LO. Hormonal causes of male sexual dysfunctions and their management (hyperprolactinemia, thyroid disorders, GH disorders, and DHEA). J Sex Med. 2013;10(3):661-677. doi:10.1111/j.17436109.2012.02735.x

67. Murray KS, James A, McGeady JB, Reed ML, Kuang WW, Nangia AK. The effect of the new 2010 World Health Organization criteria for semen analyses on male infertility. Fertil Steril. 2012;98(6):1428-1431. doi:10.1016/j. fertnstert.2012.07.1130.

68. O'Flynn O'Brien KL, Varghese AC, Agarwal A. The genetic causes of male factor infertility: a review. Fertil Steril. 2010;93(1):1-12. doi:10.1016/j.fertnstert.2009.10.045.

69. Saleh RA, Agarwal A, Nelson DR, et al. Increased sperm nuclear DNA damage in normozoospermic infertile men: a prospective study. Fertil Steril. 2002;78(2):313-318.

70. Sánchez-Martín P, Sánchez-Martín F, González-Martínez M, Gosálvez J. Increased pregnancy after a reduced male abstinence. Syst Biol Reprod Med. 2013;59:256-60.

71. Schiff JD, Ramírez ML, Bar-Chama N. Medical and surgical management male infertility. Endocrinol Metab Clin North Am. 2014;36(2):313-341.

72. Storey AE, Noseworthy DE, Delahunty KM, Halfyard SJ, McKay DW. The effects of social context on the hormonal and behavioral responsiveness of human fathers. Horm Behav. 2011;60(4):353-361. doi:10.1016/j.yhbeh.2011.07.001

73. Suarez SS. Control of hyperactivation in sperm. Hum Reprod Update. 2014;14(6):647-657.

74. Sukprasert M, Wongkularb A, Rattanasiri S, Choktanasiri W, Satirapod C. The effect of short abstinence time on sperm motility, morphology and mDNA damage. Andrology. 2013;2(1):1000107.

75. Tesarik J, Greco E, Mendoza C. Late, but not early, the paternal effect on human embryo development is related to sperm DNA fragmentation. Hum Reprod. 2014;19(3):611645.

76. van der Meij L, Almela M, Buunk AP, Fawcett TW, Salvador A. Men with elevated testosterone levels show more affiliative behaviours during interactions with women. Proc Biol Sci. 2012;279(1726):202-208. doi:10.1098/rspb.2011.0764

77. Van Peperstraten A, Proctor ML, Johnson NP, Philipson G. Techniques for surgical retrieval of sperm prior to intra-cytoplasmic sperm injection (ICSI) for azoospermia. Cochrane Database Syst Rev. 2008(2):CD002807. doi:10.1002/14651858.CD002807.pub3

78. Walsh TJ, Croughan MS, Schembri M, Chan JM, Turek PJ. Increased risk of testicular germ cell cancer among infertile men. Arch Intern Med. 2009;169(4):351-356. doi:10.1001/ archinternmed.2008.562

79. Yerram N, Sandlow JI, Brannigan RE. Clinical implications of the new 2010 WHO reference ranges for human semen characteristics. J Androl. 2012;33(3):289-290.

80. Zhu JL, Basso O, Obel C, Bille C, Olsen J. Infertility, infertility treatment, and congenital malformations: Danish national birth cohort. BMJ. 2006;333(7570):679. doi:10.1136/ bmj.38919.495718.AE.

Copyright $\odot 2017$ The Author(s); This is an open-access article distributed under the terms of the Creative Commons Attribution License (http://creativecommons.org/licenses/by/4.0), which permits unrestricted use, distribution, and reproduction in any medium, provided the original work is properly cited. 